\title{
Evaluation of Fatty Acid and Amino Acid Compositions in Okra (Abelmoschus esculentus) Grown in Different Geographical Locations
}

\author{
Rokayya Sami, ${ }^{1,2}$ Jiang Lianzhou, ${ }^{1}$ Li Yang, ${ }^{1}$ Ying Ma, ${ }^{3}$ and Jing Jing ${ }^{3}$ \\ ${ }^{1}$ Department of Food Science, Northeast Agricultural University, Harbin, Heilongjiang 150030, China \\ ${ }^{2}$ Department of Home Economics, Faculty of Education Quality, Mansoura University, Mansoura, Dakahlia 35516, Egypt \\ ${ }^{3}$ School of Food Science and Engineering, Harbin Institute of Technology, Harbin, Heilongjiang 150090, China \\ Correspondence should be addressed to Jiang Lianzhou; jlzname@163.com
}

Received 29 July 2013; Accepted 23 August 2013

Academic Editor: Gail B. Mahady

Copyright ( 2013 Rokayya Sami et al. This is an open access article distributed under the Creative Commons Attribution License, which permits unrestricted use, distribution, and reproduction in any medium, provided the original work is properly cited.

\begin{abstract}
Okra has different uses as a food and a remedy in traditional medicine. Since it produces many seeds, distribution of the plant is also quite easy. Although seed oil yield is low (4.7\%), since the linoleic acid composition of the seed oil is quiet high (67.5\%), it can still be used as a source of (UNSAT) unsaturated fatty acids. In this study, samples of okra grown in four different locations were analyzed to measure fatty acid and amino acid compositions. The content of the lipid extraction ranged from $4.34 \%$ to $4.52 \%$ on a dry weight basis. Quantitatively, the main okra fatty acids were palmitic acid (29.18-43.26\%), linoleic acid (32.22-43.07\%), linolenic acid (6.79-12.34\%), stearic acid (6.36-7.73\%), oleic acid (4.31-6.98\%), arachidic acid (ND-3.48\%), margaric acid (1.44-2.16\%), pentadecylic acid (0.63-0.92\%), and myristic acid (0.21-0.49\%). Aspartic acid, proline, and glutamic acids were the main amino acids in okra pods, while cysteine and tyrosine were the minor amino acids. Statistical methods revealed how the fatty acid and amino acid contents in okra may be affected by the sampling location.
\end{abstract}

\section{Introduction}

Okra (Abelmoschus esculentus) is widely distributed in tropical to subtropical regions in Africa, Asia, Southern Europe, Mediterranean countries, and America. Okra is mainly grown as a vegetable in the plains of Egypt. It grows well under warm climatic conditions (temperatures above $26^{\circ} \mathrm{C}$ ).

The seeds of mature okra pods are sometimes used for poultry feeding and are also consumed after roasting and as a coffee substitute. They are considered to be a stomachic stimulant, antispasmodic, and nervine [1]. Okra seeds have been used on a small scale for oil production. Okra seeds from Greece are a potential source of oil, with concentrations varying from $15.9 \%$ to $20.7 \%$ [2]. The oil mainly consists of linoleic acid (up to 47.4\%) [3]. Okra seed oil is a rich source of unsaturated fatty acids. The use of natural components in reducing cardiovascular diseases, cerebrovascular diseases, and cancer mortality has gained considerable attention. Lipid components greatly contribute to the nutritional and sensory value of almost all types of foods. Nature provides a large number of fats that differ in their chemical and functional properties. Four classes of lipids are habitually found in vegetable oils: triacylglycerols, diacylglycerols, polar lipids, and free fatty acids. The fatty acid composition determines the physical properties, stability, and nutritional value of lipids.

The most naturally occurring storage lipids are triacylglycerols. Triacylglycerols are natural compounds that consist of saturated and unsaturated fatty acids that differ in the length of their acyl chains and the number and positions of double bonds: saturated, monoenoic, and polyunsaturated fatty acids that differ with respect to detailed fatty acid composition. Monoenoic fatty acids and polyunsaturated fatty acids are structurally distinguished by the presence of repeating methylene units. These units produce an extremely flexible chain that rapidly reorients through conformational states and constitutes an influential group of molecules that 
promote health [4]. Proteins play a particularly important role in human nutrition. The amino acid contents, proportions, and their digestibility by humans characterize a protein's biological value [5]. Okra has been called "a perfect villager's vegetable" because of its robust nature, dietary fiber, and distinct seed protein balance of both lysine and tryptophan amino acids (unlike the proteins of cereals and pulses) $[6,7]$. The essential and nonessential amino acids in okra are comparable to those in soybeans. Hence, it plays a vital role in the human diet [8].

The aim of the present study was to investigate and compare total lipid, fatty acid, and amino acid composition in okra. In addition, the study was designed to obtain a comprehensive and detailed profile of the different components of okra pods, which may be of both industrial and nutritional interests.

\section{Materials and Methods}

2.1. Plant Material. Okra pods were collected from different locations in Egypt: $S$ pod (Suez) near the desert, $M$ pod (Mansoura) near the Nile River, K pod (Kafr El-Sheikh) near the Mediterranean sea, and D pod (Dakahlia) near a lake. The pods were sun-dried, and their contents were analyzed. Table 1 presents more information about the geographical origins and lipid contents.

2.2. Soxhlet Extraction of Lipids. Lipids were extracted using the method of Soxhlet [9]. All solvents were of reagent grade and purchased from Sigma Chemical Co. (St Louis, MO, USA) and were used without any further purification. About $15 \mathrm{~g}$ of okra was ground in a coffee mill and immediately extracted, in duplicate, with $200 \mathrm{~mL}$ of hexane and heated at $35-60^{\circ} \mathrm{C}$ for $6 \mathrm{~h}$ at the rate of $2-3$ drops/s. Hexane was removed using a rotary evaporator at $40^{\circ} \mathrm{C}$ in a vacuum, and the extracts were dried to a constant weight; then, the residue was stored at $-20^{\circ} \mathrm{C}$ in the dark for fatty acid analysis $[10,11]$.

\subsection{Fatty Acid Measurement}

Fatty Acid Methyl Ester Preparation. Fatty acid methyl esters (FAMEs) were prepared according to [12]. An aliquot (1 mL) of total lipids was evaporated in a tube of methylation. Fatty acids were saponified with $10 \mathrm{~mL}$ of methanolic sodium hydroxide solution $(0.5 \mathrm{M})$ for $15 \mathrm{~min}$ in a boiling water bath at $65^{\circ} \mathrm{C}$. For transmethylation, the mixture was homogenized with $10 \mathrm{~mL}$ of methanolic solution of $\mathrm{BF}_{3}(20 \%$, w/v), and the reaction was allowed to proceed for $5 \mathrm{~min}$. FAMEs were extracted twice with $10 \mathrm{~mL}$ of petroleum ether and $10 \mathrm{~mL}$ of water being added to the mixture.

2.4. Gas Chromatography and Gas Chromatography-Mass Spectrometry Analyses. FAMEs were analyzed using gasliquid chromatography (model HP 6890; Agilent, Palo Alto, CA, USA) equipped with a flame ionization detector. An SP2560 fused silica capillary column (i.d., $100 \mathrm{~m} \times 0.25 \mathrm{~mm}$; film thickness, $0.2 \mu \mathrm{m}$; Supelco, Inc., Bellefonte, PA, USA) was used. The column parameters were as follows: initial column
TABLE 1: Lipid content and geographic location of the four okra samples.

\begin{tabular}{lcccc}
\hline City & Code & Latitude & Longitude & $\begin{array}{c}\text { Total Lipids, } \\
\text { g/100 g DW }\end{array}$ \\
\hline Dakahlia & D & 31.053103 & 31.580615 & $4.45 \pm 0.01^{\mathrm{B}}$ \\
Mansoura & M & 31.042536 & 31.380014 & $4.34 \pm 0.01^{\mathrm{C}}$ \\
Kafr El-Shaikh & K & 31.347304 & 30.80246 & $4.44 \pm 0.02^{\mathrm{B}}$ \\
Suez & S & 29.984721 & 32.524309 & $4.52 \pm 0.02^{\mathrm{A}}$ \\
\hline
\end{tabular}

Values are the average of three individual samples each analyzed in duplicate \pm standard deviation. Different uppercase superscript letters, respectively, indicate significant difference $(P<0.05)$ analyzed by Duncan's multiple range test. Contents were determined by Soxhlet apparatus.

temperature was held at $40^{\circ} \mathrm{C}$ for $5 \mathrm{~min}$ after injection, $20^{\circ} \mathrm{C} / \mathrm{min}$ to $220^{\circ} \mathrm{C}$, and finally the temperature was held at $220^{\circ} \mathrm{C}$ for $30 \mathrm{~min}$. Helium was the carrier gas, with the column inlet pressure set at $17 \mathrm{psi}$. The detector temperature was $250^{\circ} \mathrm{C}$. For identification purposes, these analyses were also performed with a gas chromatograph (model HP 6890; Agilent) coupled with a 5973 mass spectrometer detector (Agilent) by using the same column described previously.

FAMEs were identified by using standards (Supelco 37 Component FAME mix; Supelco Bellefonte, PA, USA) and comparing their mass-spectral data with the mass-spectral database in the Wiley 7.0 library (HPMass Spectral Libraries, Palo Alto, CA, USA). The conjugated linoleic acid peaks were identified by comparison with the retention times of the reference standard (conjugated linoleic acid methyl ester, a mixture of cis-9, trans-11 octadecadienoic acid methyl ester and cis-10, trans-12 octadecadienoic acid methyl ester; Sigma Chemical Co.). Fatty acid contents were expressed as the proportion of each individual fatty acid to the total amount of all fatty acids present in the sample.

2.5. Amino Acid Measurement. Sample aliquots containing around $8-12 \mathrm{mg}$ of proteins were placed in a $20-\mathrm{mL}$ cuvette and mixed with $9 \mathrm{~mL}$ of $6 \mathrm{M} \mathrm{HCl} \mathrm{[13].} \mathrm{After} \mathrm{sealing} \mathrm{the}$ cuvette, the samples were hydrolyzed at $110^{\circ} \mathrm{C}$ for $24 \mathrm{~h}$ under $\mathrm{N}^{2}$. The hydrolysates were transferred into a $100 \mathrm{~mL}$ volumetric flask, mixed with $9 \mathrm{~mL}$ of $6 \mathrm{M} \mathrm{NaOH}$, and diluted with $0.02 \mathrm{~N} \mathrm{HCl}$. Then, all the samples were filtered and loaded in a Hitachi L-8800 amino acid analyzer (Tokyo, Japan) for amino acid analysis.

2.6. Statistical Analysis. Data from the replications of all varieties were subjected to a variance analysis (ANOVA) using SPSS 16.0 for Windows. Significant differences between the means were determined by Duncan's new multiple range test $(P<0.05)$. The correlation between all the studied parameters was determined by the principal component analysis (PCA) using XLSTAT software.

\section{Results and Discussion}

3.1. Results of the Fatty Acid Analysis. The fatty acid composition of the lipids extracted from sun-dried okra plants is 
TABLE 2: Fatty acid composition (\%).

\begin{tabular}{|c|c|c|c|c|}
\hline & $\mathrm{S}$ & $\mathrm{K}$ & $\mathrm{M}$ & $\mathrm{D}$ \\
\hline Myristic acid (C14:0) & $0.25 \pm 0.02^{\mathrm{B}}$ & $0.49 \pm 0.24^{\mathrm{A}}$ & $0.46 \pm 0.10^{\mathrm{AB}}$ & $0.21 \pm 0.04^{\mathrm{B}}$ \\
\hline Pentadecylic acid (C15:0) & $0.63 \pm 0.01^{\mathrm{B}}$ & $0.70 \pm 0.08^{\mathrm{B}}$ & $0.70 \pm 0.06^{\mathrm{A}}$ & $0.92 \pm 0.07^{\mathrm{A}}$ \\
\hline Palmitic acid (C16:0) & $29.18 \pm 0.35^{\mathrm{B}}$ & $43.26 \pm 0.11^{\mathrm{A}}$ & $38.95 \pm 2.37^{\mathrm{A}}$ & $39.51 \pm 0.40^{\mathrm{A}}$ \\
\hline Margaric acid (C17:0) & $1.44 \pm 0.02^{\mathrm{C}}$ & $1.50 \pm 0.06^{\mathrm{C}}$ & $1.66 \pm 0.05^{\mathrm{B}}$ & $2.16 \pm 0.10^{\mathrm{A}}$ \\
\hline Linoleic acid (C18:2) & $43.07 \pm 0.24^{\mathrm{A}}$ & $34.40 \pm 2.63^{\mathrm{B}}$ & $33.74 \pm 0.95^{\mathrm{B}}$ & $32.22 \pm 0.12^{\mathrm{B}}$ \\
\hline Oleic acid (C18:1) & $4.31 \pm 0.24^{\mathrm{B}}$ & $4.55 \pm 2.00^{\mathrm{AB}}$ & $4.47 \pm 0.77^{\mathrm{AB}}$ & $6.98 \pm 0.29^{\mathrm{A}}$ \\
\hline Linolenic acid (C18:3) & $12.34 \pm 0.16^{\mathrm{A}}$ & $7.82 \pm 0.94^{\mathrm{C}}$ & $10.07 \pm 1.06^{\mathrm{B}}$ & $6.79 \pm 0.75^{\mathrm{C}}$ \\
\hline Stearic acid (C18:0) & $6.36 \pm 0.07^{\mathrm{D}}$ & $7.28 \pm 0.16^{\mathrm{B}}$ & $6.98 \pm 0.23^{\mathrm{C}}$ & $7.73 \pm 0.30^{\mathrm{A}}$ \\
\hline Arachidic acid (C20:0) & $2.42 \pm 0.04^{\mathrm{C}}$ & ND & $2.96 \pm 0.12^{\mathrm{B}}$ & $3.48 \pm 0.13^{\mathrm{A}}$ \\
\hline Total SAT & $40.28 \pm 0.33^{\mathrm{B}}$ & $53.23 \pm 0.27^{\mathrm{A}}$ & $51.71 \pm 2.15^{\mathrm{A}}$ & $54.01 \pm 0.95^{\mathrm{A}}$ \\
\hline Total UNSAT & $59.72 \pm 0.33^{\mathrm{A}}$ & $46.77 \pm 0.27^{\mathrm{B}}$ & $48.29 \pm 2.15^{\mathrm{B}}$ & $45.99 \pm 0.95^{\mathrm{B}}$ \\
\hline Total SAT/Total UNSAT & $67.44 \pm 0.01^{\mathrm{B}}$ & $113.81 \pm 0.01^{\mathrm{A}}$ & $107.08 \pm 0.10^{\mathrm{A}}$ & $117.44 \pm 0.04^{\mathrm{A}}$ \\
\hline Total PUFA & $55.42 \pm 0.09^{\mathrm{A}}$ & $42.22 \pm 1.75^{\mathrm{B}}$ & $43.82 \pm 1.67^{\mathrm{B}}$ & $39.01 \pm 0.66^{\mathrm{C}}$ \\
\hline Total MUFA & $4.31 \pm 0.24^{\mathrm{B}}$ & $4.55 \pm 2.00^{\mathrm{AB}}$ & $4.47 \pm 0.77^{\mathrm{AB}}$ & $6.98 \pm 0.29^{\mathrm{A}}$ \\
\hline
\end{tabular}

Each value is presented as the mean \pm standard deviation $(n=3)$. Data with different uppercase superscript letters in the same column of variety respectively indicate significant difference $(P<0.05)$ analyzed by Duncan's multiple range test. ND: Non-detected

presented in Table 2. The okra plants had a low amount of oils. The lipid content did not vary significantly among okra pods; it ranged from $4.34 \mathrm{~g} / 100 \mathrm{~g}$ for $\mathrm{M}$ pods to $4.52 \mathrm{~g} / 100 \mathrm{~g}$ for S pods. All the studied okra pods had higher fat content than the values previously reported for okra [14]. An examination of FAME derivatives showed nine fatty acids. The total saturated fatty acids (SFA), monounsaturated fatty acids (MUFA), and polyunsaturated fatty acids (PUFA) showed significant variation in their contents. Palmitic acid (29.18-43.26\%) was the major fatty acid; it promotes natural oil regeneration. Oil is an important component for the skin to retain its protective barrier. With too little oil, the skin will crack and bleed, resulting in a greater risk of infection and disease. The next most common fatty acid was linoleic acid (32.22$43.07 \%$ ), which was most abundant in the S pod, followed by linolenic acid (6.79-12.34\%), stearic acid (6.36-7.73\%), oleic acid (4.31-6.98\%), arachidic acid (ND-3.48\%), margaric acid (1.44-2.16\%), pentadecylic acid (0.63-0.92\%), and myristic acid $(0.21-0.49 \%)$. Figure 1 shows chromatograms of a fatty acid sample. In all the cases, saturated fatty acids (SAT) predominated over SFA, ranging from $67 \%$ to $117 \%$, and particularly, PUFA predominated over MUFA. Nine fatty acids were identified and quantified. To the best of our knowledge, there are no previous reports on the fatty acid composition of okra pods. The present study proved that okra pods are a source of beneficial fatty acids such as the polyunsaturated fatty acids linoleic and $\alpha$-linolenic acid. Linoleic acid is a member of the group of essential fatty acids called omega- 6 fatty acids, so called because they are an essential dietary requirement for all mammals and promote the biosynthesis of arachidonic acid, and thus, some prostaglandins. Linoleic acid is used in making soaps, emulsifiers, and quick-drying oils. It has become increasingly popular in the cosmetics industry because of its beneficial properties on the skin, including anti-inflammatory, acne-reduction, and moisture-retention properties [15]. Studies have found evidence that $\alpha$-linolenic acid, a polyunsaturated omega- 3 fatty acid, is related to

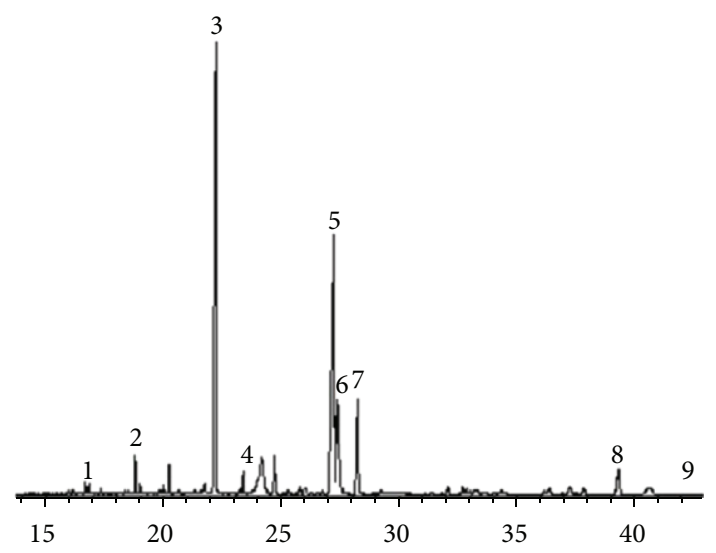

FIGURE 1: Typical chromatogram of fatty acid methyl ester prepared from K pod variety oil. Peaks: 1, Myristic acid; 2, Pentadecylic acid; 3, Palmitic acid; 4, Margaric acid; 5, Linoleic acid; 6, Oleic acid; 7, Linolenic acid; 8, Stearic acid; 9, Arachidic acid.

a lower risk of cardiovascular disease [16]. Prostaglandins and thromboxanes are related compounds known as eicosanoids, which have a large variety of biological activities, including mediation in anti-inflammatory processes, lowering of blood pressure, relaxation of coronary arteries, and inhibition of platelet aggregation [17].

3.2. Results of the Amino Acid Analysis. The amino acid profile of the okra plants is shown in Table 3, listing the concentrations of 17 amino acids. Among these amino acids, 11 essential amino acids were found. The major amino acids were aspartic acid (2.91-4.92 g/100 g), followed by proline, glutamic acid, arginine, leucine, alanine, lysine, serine, and phenylalanine. Methionine, isoleucine, histidine, cysteine, and tyrosine were the minor amino acids in okra pods. The major acids constituted more than $76.45 \%$ of the total amino acids present in the proteins of the okra plants. The total 
TABLE 3: Amino acid composition (\%).

\begin{tabular}{|c|c|c|c|c|}
\hline & $\mathrm{S}$ & $\mathrm{K}$ & M & $\mathrm{D}$ \\
\hline Ile & $0.29 \pm 0.03^{\mathrm{AB}}$ & $0.31 \pm 0.05^{\mathrm{A}}$ & $0.29 \pm 0.05^{\mathrm{AB}}$ & $0.22 \pm 0.03^{\mathrm{B}}$ \\
\hline Leu & $0.70 \pm 0.08^{\mathrm{AB}}$ & $0.72 \pm 0.10^{\mathrm{AB}}$ & $0.78 \pm 0.15^{\mathrm{A}}$ & $0.56 \pm 0.04^{\mathrm{A}}$ \\
\hline Lys & $0.59 \pm 0.07^{\mathrm{AB}}$ & $0.69 \pm 0.09^{\mathrm{A}}$ & $0.68 \pm 0.12^{\mathrm{A}}$ & $0.50 \pm 0.05^{\mathrm{B}}$ \\
\hline Met & $0.07 \pm 0.02^{\mathrm{AB}}$ & $0.06 \pm 0.02^{\mathrm{AB}}$ & $0.08 \pm 0.02^{\mathrm{A}}$ & $0.05 \pm 0.01^{\mathrm{B}}$ \\
\hline Cys & $0.17 \pm 0.03^{\mathrm{B}}$ & $0.17 \pm 0.01^{\mathrm{B}}$ & $0.22 \pm 0.03^{\mathrm{A}}$ & $0.14 \pm 0.02^{\mathrm{B}}$ \\
\hline Total sulphuric acids & $0.24 \pm 0.02^{\mathrm{B}}$ & $0.23 \pm 0.03^{\mathrm{B}}$ & $0.30 \pm 0.05^{\mathrm{A}}$ & $0.19 \pm 0.02^{\mathrm{B}}$ \\
\hline Tyr & $0.37 \pm 0.04^{\mathrm{AB}}$ & $0.37 \pm 0.05^{\mathrm{AB}}$ & $0.44 \pm 0.08^{\mathrm{A}}$ & $0.30 \pm 0.00^{\mathrm{B}}$ \\
\hline Phe & $0.47 \pm 0.05^{\mathrm{AB}}$ & $0.48 \pm 0.06^{\mathrm{AB}}$ & $0.52 \pm 0.12^{\mathrm{A}}$ & $0.36 \pm 0.04^{\mathrm{B}}$ \\
\hline Total aromatic amino acids & $0.83 \pm 0.09^{\mathrm{AB}}$ & $0.86 \pm 0.11^{\mathrm{AB}}$ & $0.96 \pm 0.20^{\mathrm{A}}$ & $0.66 \pm 0.04^{\mathrm{B}}$ \\
\hline Thr & $0.45 \pm 0.05^{\mathrm{A}}$ & $0.45 \pm 0.06^{\mathrm{A}}$ & $0.53 \pm 0.12^{\mathrm{A}}$ & $0.38 \pm 0.04^{\mathrm{A}}$ \\
\hline Val & $0.46 \pm 0.05^{\mathrm{A}}$ & $0.47 \pm 0.06^{\mathrm{A}}$ & $0.45 \pm 0.08^{\mathrm{A}}$ & $0.34 \pm 0.04^{\mathrm{B}}$ \\
\hline His & $0.24 \pm 0.03^{\mathrm{B}}$ & $0.24 \pm 0.03^{\mathrm{B}}$ & $0.33 \pm 0.05^{\mathrm{A}}$ & $0.23 \pm 0.01^{B}$ \\
\hline Arg & $0.67 \pm 0.07^{\mathrm{C}}$ & $0.75 \pm 0.09^{\mathrm{BC}}$ & $1.44 \pm 0.17^{\mathrm{A}}$ & $0.95 \pm 0.14^{\mathrm{B}}$ \\
\hline Total essential amino acids (E) & $1.82 \pm 0.19^{\mathrm{B}}$ & $1.90 \pm 0.25^{\mathrm{B}}$ & $2.75 \pm 0.35^{\mathrm{A}}$ & $1.89 \pm 0.07^{\mathrm{B}}$ \\
\hline Asp & $3.23 \pm 0.37^{\mathrm{B}}$ & $2.91 \pm 0.27^{\mathrm{B}}$ & $4.92 \pm 1.32^{\mathrm{A}}$ & $3.58 \pm 0.33^{\mathrm{AB}}$ \\
\hline Ser & $0.64 \pm 0.07^{\mathrm{A}}$ & $0.61 \pm 0.08^{\mathrm{A}}$ & $0.64 \pm 0.18^{\mathrm{A}}$ & $0.46 \pm 0.05^{\mathrm{A}}$ \\
\hline Glu & $1.99 \pm 0.23^{\mathrm{A}}$ & $1.82 \pm 0.22^{\mathrm{A}}$ & $2.44 \pm 0.86^{\mathrm{A}}$ & $1.74 \pm 0.24^{\mathrm{A}}$ \\
\hline Gly & $0.48 \pm 0.05^{\mathrm{A}}$ & $0.49 \pm 0.06^{\mathrm{A}}$ & $0.50 \pm 0.11^{\mathrm{A}}$ & $0.38 \pm 0.05^{\mathrm{A}}$ \\
\hline Ala & $0.60 \pm 0.07^{\mathrm{A}}$ & $0.61 \pm 0.08^{\mathrm{A}}$ & $0.71 \pm 0.19^{\mathrm{A}}$ & $0.53 \pm 0.08^{\mathrm{A}}$ \\
\hline Pro & $1.40 \pm 0.12^{\mathrm{B}}$ & $1.38 \pm 0.21^{\mathrm{B}}$ & $2.53 \pm 0.77^{\mathrm{A}}$ & $1.92 \pm 0.26^{\mathrm{AB}}$ \\
\hline Total nonessential amino acids (N) & $8.34 \pm 0.90^{\mathrm{AB}}$ & $7.81 \pm 0.91^{\mathrm{B}}$ & $11.73 \pm 3.42^{\mathrm{A}}$ & $8.62 \pm 0.99^{\mathrm{AB}}$ \\
\hline Total amino acid & $12.80 \pm 1.37^{\mathrm{B}}$ & $12.51 \pm 1.52^{\mathrm{B}}$ & $17.49 \pm 4.26^{\mathrm{A}}$ & $12.63 \pm 1.07^{\mathrm{B}}$ \\
\hline
\end{tabular}

Each value is presented as the mean \pm standard deviation $(n=3)$. Data with different uppercase superscript letters in the same column of variety, respectively, indicate significant difference $(P<0.05)$ analyzed by Duncan's multiple range test.

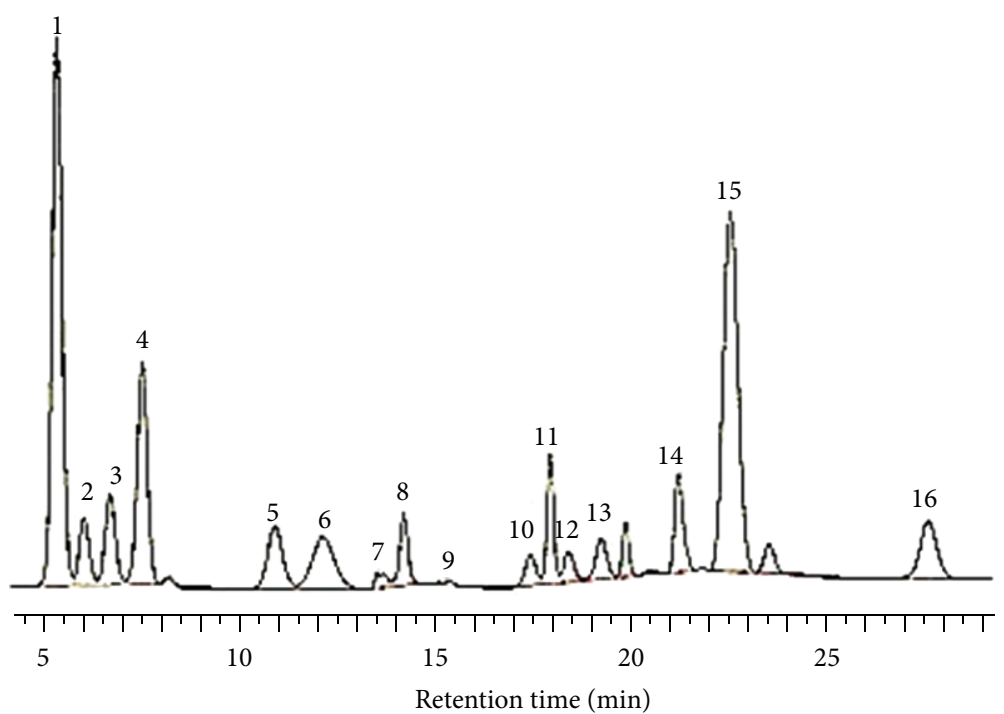

(a)

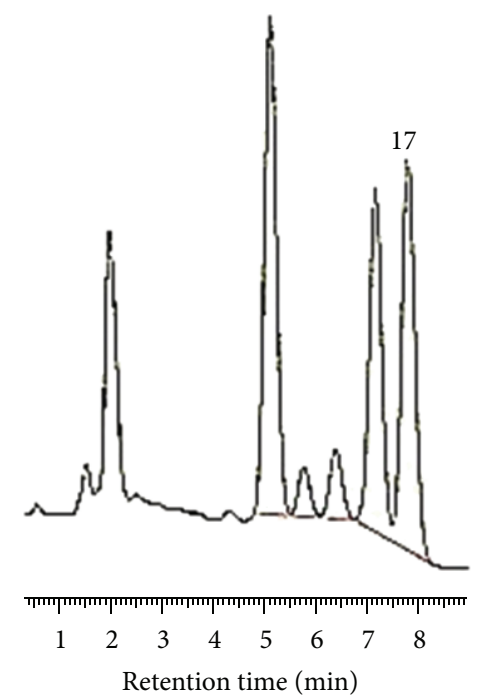

(b)

FIGURE 2: Typical chromatogram of amino acid from K pod variety. Peaks: 1, arginine; 2, threonine; 3, serine; 4, glutamic acid; 5 , glycine; 6 , alanine; 7, cysteine; 8 , valine; 9 , methionine; 10 , isoleucine; 11 , leucine; 12 , tyrosine; 13 , phenylalanine; 14 , lysine; 15 , histidine; 16 , Linolenic acid; 17 , proline. 


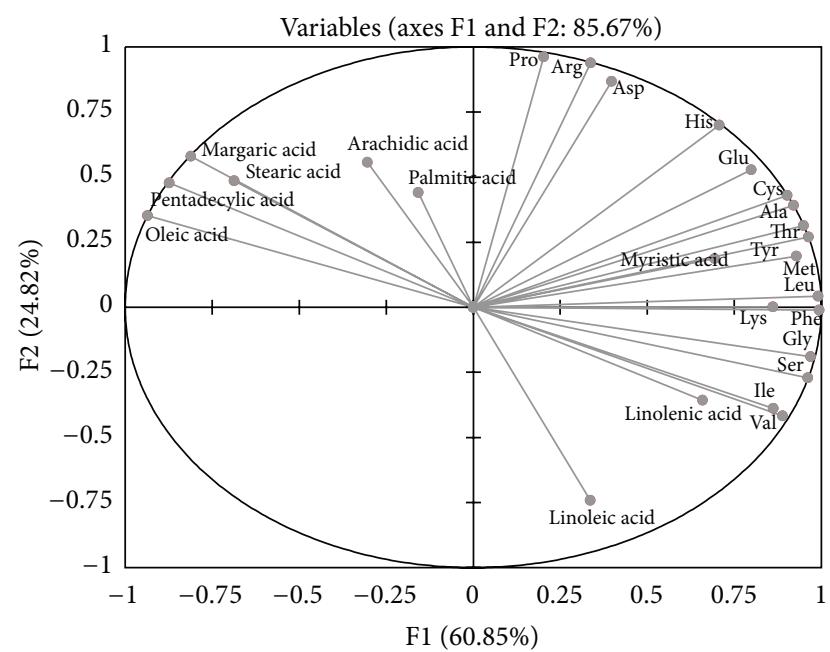

FIGURE 3: Plots of the scores for fatty and amino acids content of okra pods.

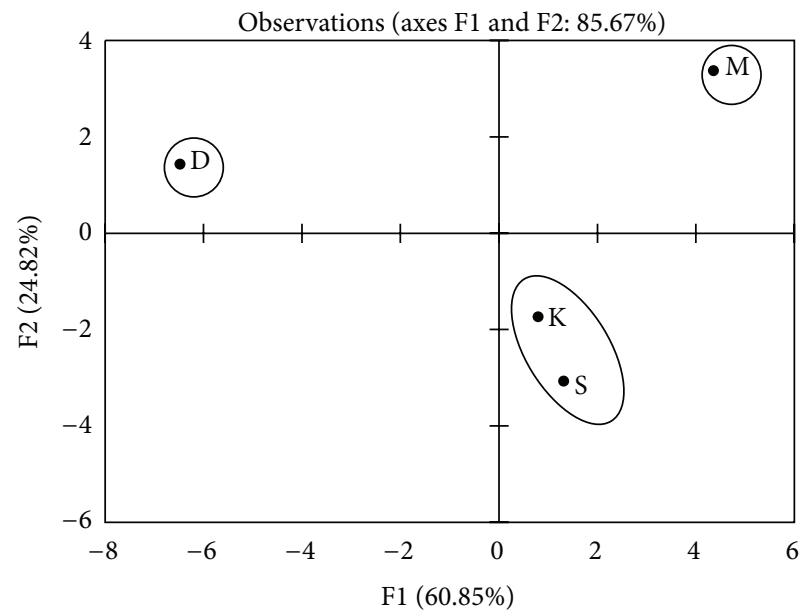

FIgURE 4: Plots of the $x$-loudings for fatty and amino acids content of okra pods.

amount of nonessential amino acids $(N)$ was higher than that of the essential amino acids $(E)$. M pod and $\mathrm{K}$ pod were found to be rich in isoleucine, lysine, and valine, with a combined concentration of $1.32 \mathrm{~g} / 100 \mathrm{~g}$ for $\mathrm{M}$ pod and $1.46 \mathrm{~g} / 100 \mathrm{~g}$ for $\mathrm{K}$ pod. However, significant differences $(P<0.05)$ in arginine, aspartic acid, and proline contents were observed between $M$ pod and $\mathrm{K}$ pod. The amount of sulfur-containing amino acids (methionine and cystine) was $0.24,0.23,0.30$, and $0.19 \mathrm{~g} / 100 \mathrm{~g}$ for $\mathrm{S}, \mathrm{K}, \mathrm{M}$, and $\mathrm{D}$ pod, respectively, while the total aromatic amino acid content was $0.66-0.96 \mathrm{~g} / 100 \mathrm{~g}$. D pod showed the lowest value, and $\mathrm{M}$ pod showed the highest value. Figure 2 shows chromatograms of the amino acid samples.

3.3. Results of the Principal Component Analysis. PCA was used to analyze the fatty acid and amino acid contents. Figures 3 and 4 present the plots of the scores and the correlation loadings, respectively. The scores plot of PCA illustrates the large variability of the four okra varieties
TABLE 4: Discriminate variables factors of principal components analysis.

\begin{tabular}{lcc}
\hline & F1 & F2 \\
\hline Proper value & 15.82 & 6.45 \\
Variability (\%) & 60.85 & 24.82 \\
Cumulative (\%) & 60.85 & 85.67 \\
Myristic acid & +3.04 & - \\
Pentadecylic acid & -4.82 & - \\
Palmitic acid & - & +3.01 \\
Margaric acid & - & +5.21 \\
Linoleic acid & - & -8.53 \\
Oleic acid & -5.53 & - \\
Linolenic acid & +2.74 & - \\
Stearic acid & - & +3.66 \\
Arachidic acid & - & +4.79 \\
Ile & +4.70 & - \\
Leu & +6.21 & - \\
Lys & +4.69 & - \\
Met & +5.44 & - \\
Cys & +5.14 & - \\
Tyr & +5.86 & - \\
Phe & +6.24 & - \\
Thr & +5.70 & - \\
Val & +4.99 & - \\
His & - & +13.67 \\
Arg & - & - \\
Asp & - & - \\
Ser & +5.84 & - \\
Glu & - & - \\
Gly & +5.94 & \\
Ala & & - \\
Pro & & - \\
\hline & & - \\
\hline
\end{tabular}

(S, M, K, and D) on the basis of their location. The loadings are the coefficients of the original variables that define each principal component [18]. Inertia percentage and correlated variables for axes 1 and 2 are displayed in Table 4. Axes 1 explained $60.85 \%$ of the total inertia. Axes 2 explained $24.82 \%$ of the inertia and was made positive by arginine, histidine, proline, and aspartic acid. The inertia was made negative by linoleic acid. Plots of the scores in Figure 3 indicated that the data cloud was mainly bidimensional. With respect to the explanatory variables, Figure 4 showed two clusters of varieties. The first cluster included the $\mathrm{S}$ and $\mathrm{K}$ pod varieties. The second cluster ( $\mathrm{D}$ and $\mathrm{M}$ pod varieties) was individualized.

\section{Conclusions}

The fatty acid and amino acid results for okra pods were in agreement with the literature. Quantitatively, total lipids ranged from $4.34 \mathrm{~g} / 100 \mathrm{~g}$ to $4.52 \mathrm{~g} / 100 \mathrm{~g}$ on a dry weight basis. Okra contents had a significant correlation with the geographical distances. SAT predominated over SFA, and PUFA 
particularly predominated over MUFA. M pod was found to be the richest in all amino acid values except isoleucine, lysine, and valine. The essential and nonessential amino acids in okra are comparable to those in soybeans. Therefore, okra could be used as a good source of proteins for human nutrition. Seeds can be subjected to oil extraction for additional benefits. Okra can be used in making soaps, emulsifiers, and quick-drying oils and has become increasingly popular in the cosmetics industry.

\section{Conflict of Interests}

The authors declare that there is no conflict of interest is regarding the publication of this paper. The present research was supported by the China Scholarship Council by a senior scholarship awarded to Rokayya Sami and by the National High-tech R\&D Program of China (863 Program) (research Grant no.: 2013AA102104).

\section{Acknowledgments}

The authors are grateful to Dr. Yang from the Harbin Institute of Technology and the Northeast Agricultural University for providing the gas chromatography-mass spectrometry analysis and amino acid analyzer facilities to carry out the present research. The authors are also grateful to the anonymous referees for helpful comments on an earlier draft. The present paper was supported by the China Scholarship Council.

\section{References}

[1] A. Prommakool, T. Sajjaanantakul, T. Janjarasskul, and J. M. Krochta, "Whey protein-okra polysaccharide fraction blend edible films: tensile properties, water vapor permeability and oxygen permeability," Journal of the Science of Food and Agriculture, vol. 91, no. 2, pp. 362-369, 2011.

[2] C. D. András, B. Simándi, F. Örsi et al., "Supercritical carbon dioxide extraction of okra (Hibiscus esculentus L) seeds," Journal of the Science of Food and Agriculture, vol. 85, no. 8, pp. 14151419, 2005.

[3] P. A. Savello, F. W. Martin, and J. M. Hill, "Nutritional composition of okra seed meal," Journal of Agricultural and Food Chemistry, vol. 28, no. 6, pp. 1163-1166, 1980.

[4] W. Vermerris and R. Nicholson, Phenolic Compound Biochemistry, Springer, Dordrecht, The Netherlands, 2006.

[5] C. Ewa, G. Agnieszka, F. Adam et al., "The content of protein and of amino acids in Jerusalem artichoke tubers (Helianthus tuberosus L.) of red variety Rote Zonenkugel," Acta Scientiarum Polonorum, Technologia Alimentaria, vol. 10, no. 4, pp. 433-441, 2011.

[6] K. Sanjeet, D. Sokona, H. Adamou et al., "Okra (Abelmoschus spp.) in West and Central Africa: potential and progress on its improvement," African Journal of Agricultural Research, vol. 5, no. 25, pp. 3590-3598, 2010.

[7] R. A. Holser and G. Bost, "Hybrid Hibiscus seed oil compositions," Journal of the American Oil Chemists' Society, vol. 81, no. 8, pp. 795-797, 2004.

[8] A. J. Farinde, O. K. Owolarafe, and O. I. Ogungbemi, "An overview of production, processing, marketing and utilisation of okra in egbedore local government area of Osun State, Nigeria," Agricultural Engineering, vol. 4, pp. 1-17, 2007.

[9] L. F. Razon, R. L. Bacani, R. L. Evangelista, and G. Knothe, "Fatty acid profile of kenaf seed oil," Journal of the American Oil Chemists' Society, vol. 90, pp. 835-840, 2013.

[10] H. S. Lam and A. Proctor, "Rapid methods for milled rice surface total lipid and free fatty acid determination," Cereal Chemistry, vol. 78, no. 4, pp. 498-499, 2001.

[11] J. D. Hubbard, J. M. Downing, M. S. Ram, and O. K. Chung, "Lipid extraction from wheat flour using supercritical fluid extraction," Cereal Chemistry, vol. 81, no. 6, pp. 693-698, 2004.

[12] L. D. Metcalfe, A. A. Schmitz, and J. R. Pelka, "Rapid preparation of fatty acid esters from lipids for gas chromatographic analysis," Analytical Chemistry, vol. 38, no. 3, pp. 514-515, 1966.

[13] H. Li, Y. Ma, A. Dong et al., "Protein composition of yak milk," Dairy Science and Technology, vol. 90, no. 1, pp. 111-117, 2010.

[14] A. H. Mohsen, "Adsorption of lead ions from aquesous solution by okra wastes," International Journal of Physical Sciences, vol. 2, no. 7, pp. 178-184, 2007.

[15] G. L. Darmstadt, M. Mao-Qiang, E. Chi et al., "Impact of topical oils on the skin barrier: possible implications for neonatal health in developing countries," Acta Paediatrica, vol. 91, no. 5, pp. 546-554, 2002.

[16] E. C. William, "Importance of $\mathrm{n}-3$ fatty acids in health and disease," The American Journal of Clinical Nutrition, vol. 71, pp. 171S-175S, 2000.

[17] G. Zubay, Biochemistry, Wm. C. Brown Publishers, Dubuque, La, USA, 5th edition, 2006.

[18] W. Elfalleh, M. Ying, N. Nasri et al., "Fatty acids from Tunisian and Chinese pomegranate (Punica granatum L.) seeds," International Journal of Food Sciences and Nutrition, vol. 62, no. 3, pp. 200-206, 2011. 

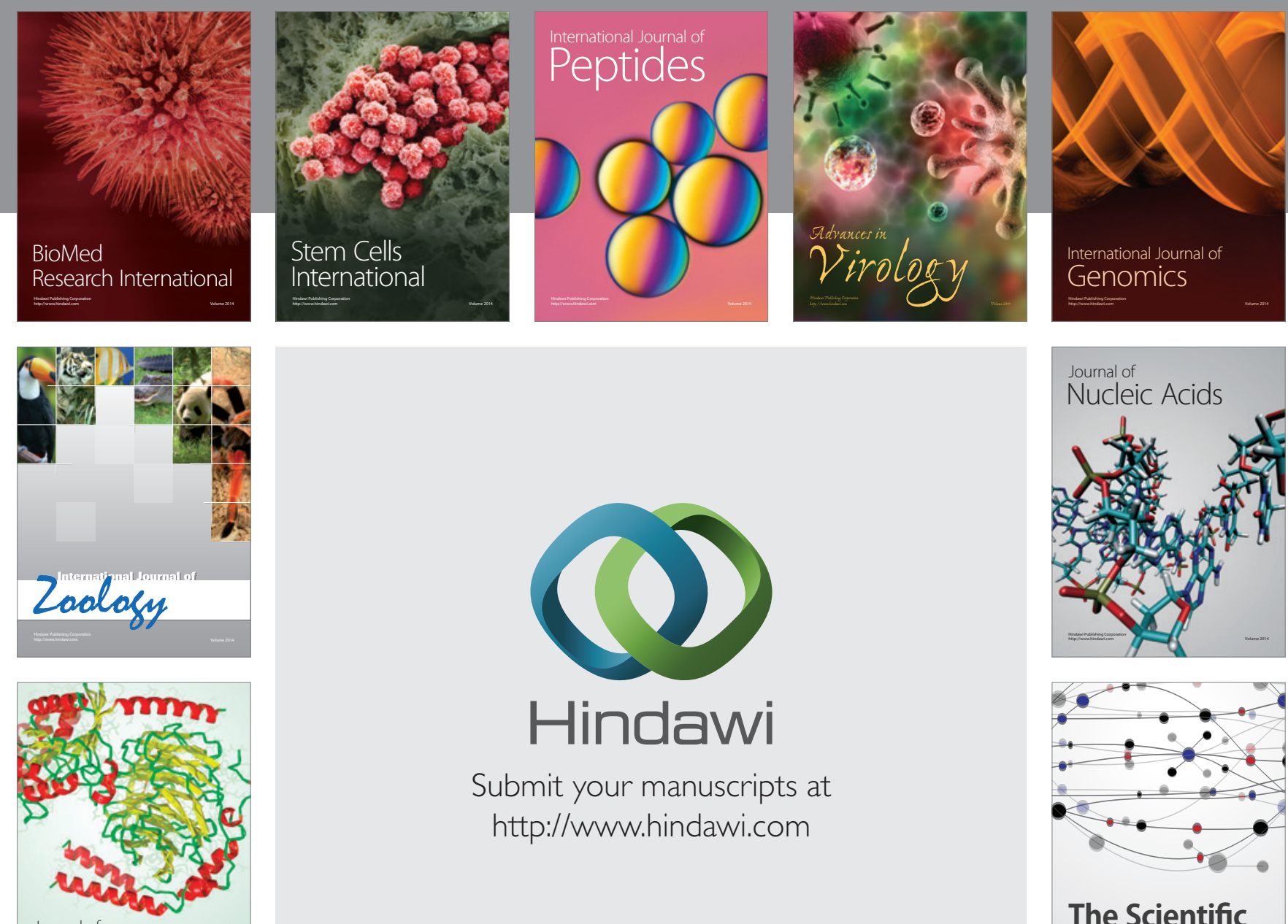

Submit your manuscripts at

http://www.hindawi.com

Journal of
Signal Transduction
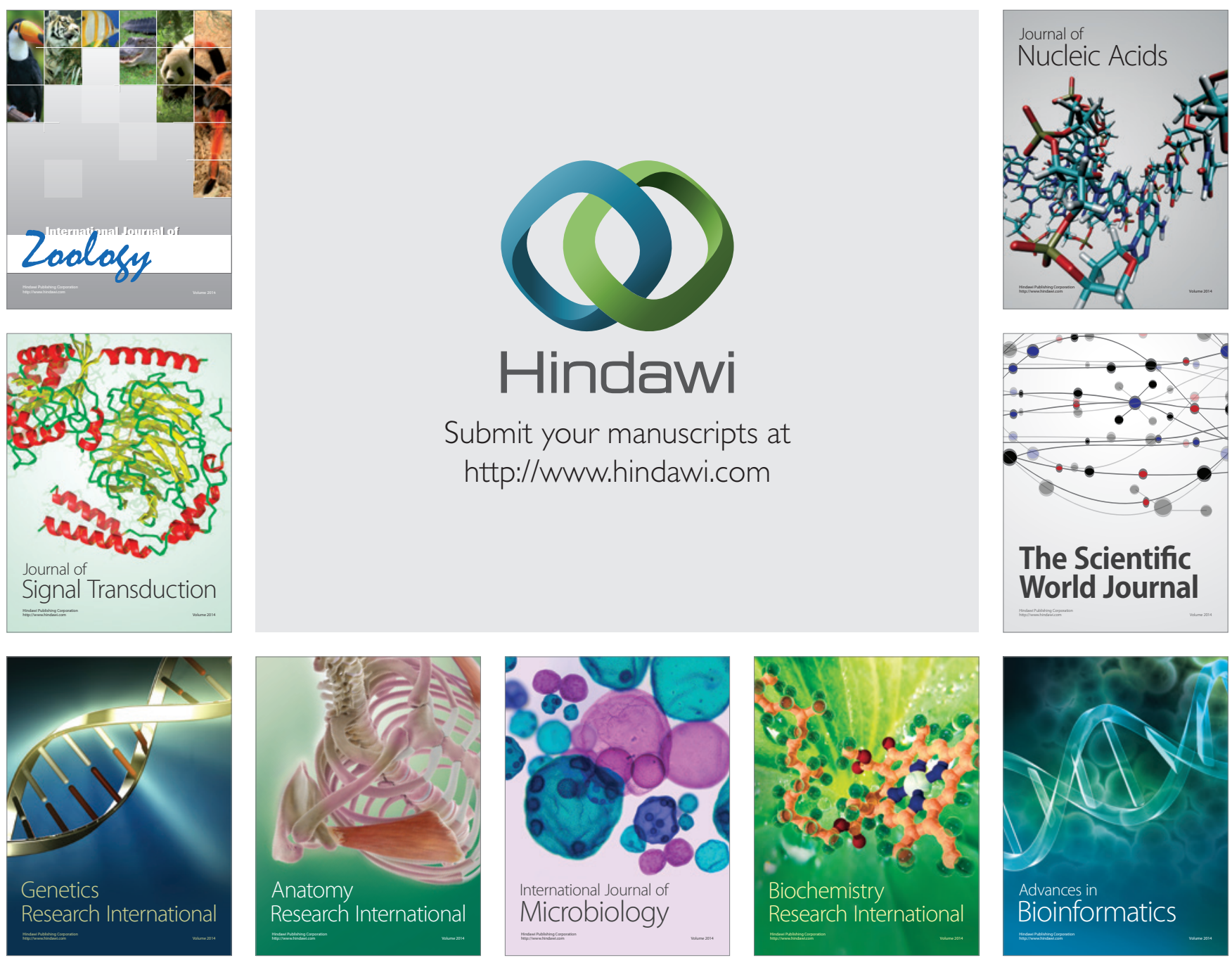

The Scientific World Journal
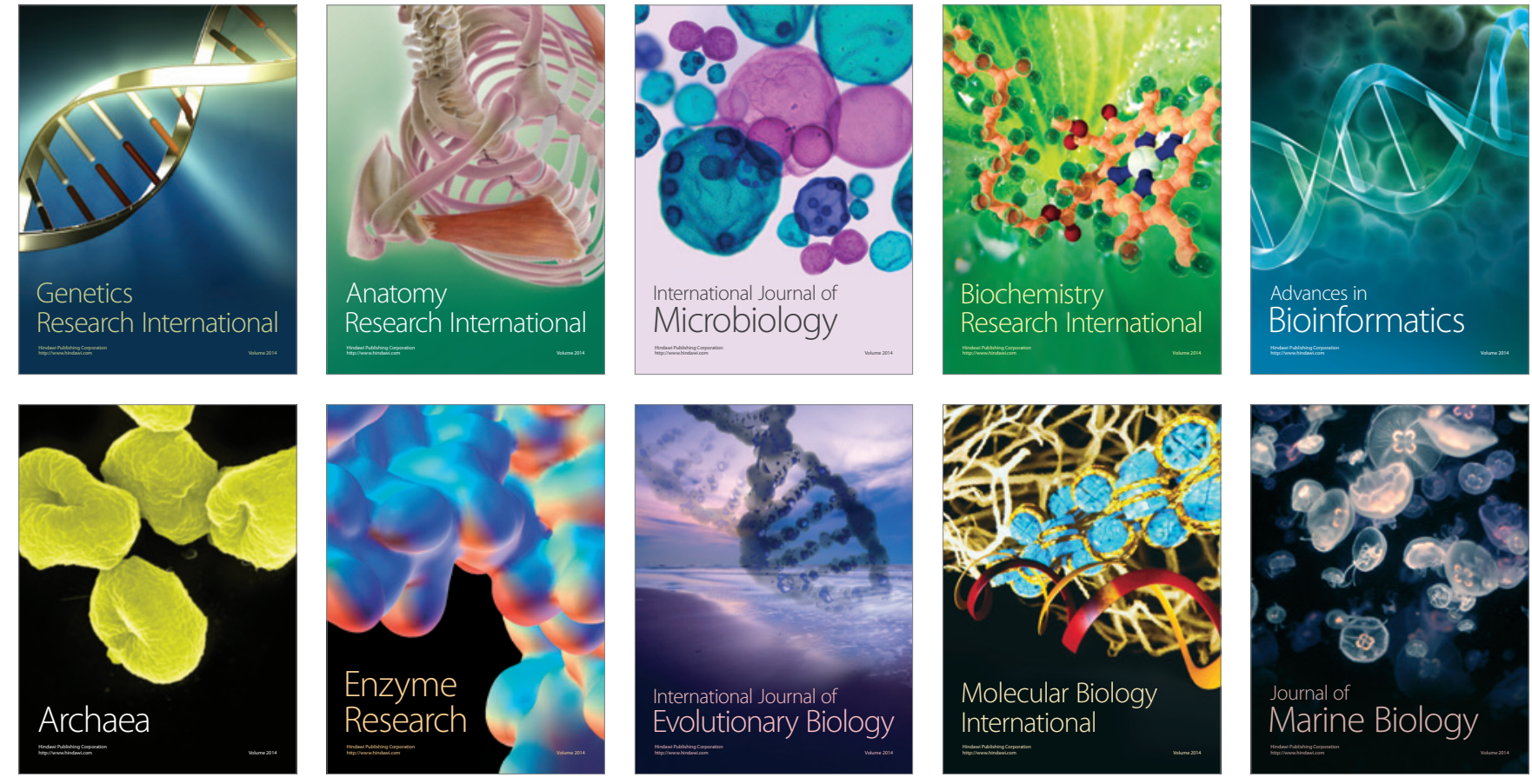